ARTICLE

Received 10 Dec 2015 | Accepted 18 May 2016 | Published 16 Jun 2016

DOI: $10.1038 /$ ncomms11981

OPEN

\title{
Nickel-vanadium monolayer double hydroxide for efficient electrochemical water oxidation
}

Ke Fan ${ }^{1,2}$, Hong Chen ${ }^{1}$, Yongfei $\mathrm{Ji}^{3}$, Hui Huang ${ }^{4}$, Per Martin Claesson ${ }^{4}$, Quentin Daniel ${ }^{1}$, Bertrand Philippe ${ }^{5}$, Håkan Rensmo ${ }^{5}$, Fusheng $\mathrm{Li}^{1}{ }^{1}$ Yi Luo $^{3}$ \& Licheng Sun ${ }^{1,6}$

Highly active and low-cost electrocatalysts for water oxidation are required due to the demands on sustainable solar fuels; however, developing highly efficient catalysts to meet industrial requirements remains a challenge. Herein, we report a monolayer of nickel-vanadium-layered double hydroxide that shows a current density of $27 \mathrm{mAcm}^{-2}$ (57 $\mathrm{mA} \mathrm{cm}^{-2}$ after ohmic-drop correction) at an overpotential of $350 \mathrm{mV}$ for water oxidation. Such performance is comparable to those of the best-performing nickel-iron-layered double hydroxides for water oxidation in alkaline media. Mechanistic studies indicate that the nickel-vanadium-layered double hydroxides can provide high intrinsic catalytic activity, mainly due to enhanced conductivity, facile electron transfer and abundant active sites. This work may expand the scope of cost-effective electrocatalysts for water splitting.

\footnotetext{
${ }^{1}$ Department of Chemistry, Organic Chemistry, KTH Royal Institute of Technology, 10044 Stockholm, Sweden. ${ }^{2}$ State Key Laboratory of Advanced Technology for Materials Synthesis and Processing, Wuhan University of Technology, Wuhan 430070, China. ${ }^{3}$ Division of Theoretical Chemistry and Biology, School of Biotechnology, KTH Royal Institute of Technology, SE-106 91 Stockholm, Sweden. ${ }^{4}$ Department of Chemistry, Surface and Corrosion Science, KTH Royal Institute of Technology, SE-10044 Stockholm, Sweden. ${ }^{5}$ Department of Physics and Astronomy, Uppsala University, Box 516, 75120 Uppsala, Sweden. ${ }^{6}$ State Key Laboratory of Fine Chemicals, DUT-KTH Joint Education and Research Center on Molecular Devices, Dalian University of Technology (DUT), Dalian 116024, China. Correspondence and requests for materials should be addressed to L.S. (email: lichengs@kth.se).
} 
W ater splitting is considered one of the most promising strategies to produce chemical fuels such as hydrogen. The half reaction of the water splitting process, water oxidation, remains the bottleneck of the whole process at present. Therefore, developing highly efficient water oxidation catalysts is crucial. Some precious metal-based electrocatalysts, such as $\mathrm{IrO}_{2}$ and $\mathrm{RuO}_{2}$, have shown excellent performance for water oxidation; however, they suffer from high-cost and relative scarcity of precious metals, which limits their applications. Although some first-row transition metal oxides (for example, $\mathrm{NiO}_{\mathrm{x}}, \mathrm{NiFeO}_{\mathrm{x}}$, $\mathrm{CoO}_{\mathrm{x}}$ and $\mathrm{MnO}_{\mathrm{x}}$ ) had been developed as low-cost electrocatalysts for water oxidation, most of them still cannot compete with $\mathrm{IrO}_{2}$ and $\mathrm{RuO}_{2}{ }^{1,2}$. Recently, the earth-abundant $\mathrm{Ni}-\mathrm{Fe}$ double-layered hydroxide (NiFe-LDH) catalysts have attracted attention ${ }^{3-7}$. From being first reported as an advanced electrocatalyst coupled with carbon nanotubes for water oxidation ${ }^{8}$, it is nowadays known as one of the most active catalysts with a low overpotential and high electrolysis current. Since, then tremendous efforts have been devoted to further improve the activity of NiFe-LDH, such as exfoliation ${ }^{9}$ and hybridization $6,8,10,11$, to the extent that $\mathrm{LDH}$ catalysts can now outperform $\mathrm{IrO}_{2}$ in alkaline media ${ }^{6,8,9}$; however, the aforementioned methods are still too complicated for large-scale applications.

It is already known that $\mathrm{Fe}(\mathrm{III})$ incorporated in $\mathrm{Ni}(\mathrm{II})$-based $\mathrm{LDH}$ is the key aspect for the high catalytic performance, although the role of $\mathrm{Fe}$ in LDH is still ambiguous ${ }^{5,6,12}$. Besides $\mathrm{Fe}(\mathrm{III})$, cobalt is also commonly incorporated in nickel hydroxides to construct NiCo-LDHs for water oxidation ${ }^{13-16}$, and the resulting NiCo-LDHs show promising catalytic activities; however, the performance is relatively low compared with the reported NiFe-LDHs under identical conditions ${ }^{9}$. Besides, more earth-abundant metal elements have been incorporated into $\mathrm{Ni}(\mathrm{OH})_{2}$ to explore novel LDHs for water oxidation, for example, recently Koper and co-workers ${ }^{17}$ investigated a series of Ni-based double hydroxides with $\mathrm{Cr}, \mathrm{Mn}, \mathrm{Fe}, \mathrm{Co}, \mathrm{Cu}$ and $\mathrm{Zn}$ for water oxidation, and among these candidates NiFe-LDH still appears as the most promising and shows the best activity. Up until now, there has been no reported earth-abundant metal element that can outperform Fe incorporated Ni-based LDHs. Searching for an earth-abundant metal to form efficient Ni-based LDH comparable to NiFe-LDH is still the state-of-the-art in this area of energy research.

In this work, we incorporate another earth-abundant element into $\mathrm{Ni}(\mathrm{OH})_{2}$ : vanadium, and succeed in forming $\mathrm{NiV}-\mathrm{LDH}$ as an efficient catalyst for the water oxidation reaction. A simple one-step hydrothermal method is employed to synthesize NiV-LDH. Without need for exfoliation or hybridization with other materials, the resulting monolayer NiV-LDH catalyst exhibits comparable activity to the best-performing NiFe-LDH for water oxidation in alkaline electrolyte.

\section{Results}

Monolayer of $\mathbf{N i}_{0.75} \mathbf{V}_{\mathbf{0 . 2 5}}-\mathrm{LDH}$. Figure 1a shows the typical $\mathrm{X}$-ray diffraction patterns of pure $\mathrm{Ni}(\mathrm{OH})_{2}$ and $\mathrm{Ni}_{0.75} \mathrm{~V}_{0.25}-\mathrm{LDH}$. As can be seen, pure $\mathrm{Ni}(\mathrm{OH})_{2}$ was successfully synthesized in the simple hydrothermal system without addition of $\mathrm{V}$ sources, and the X-ray diffraction pattern supports the formation of pure hexagonal $\alpha-\mathrm{Ni}(\mathrm{OH})_{2}$ (JCPDS 380715), which exhibits a layered structure constructed from $\left[\mathrm{NiO}_{6}\right]$ coordinated octahedra connected by sharing their edges. After incorporation of $\mathrm{V}$ into the structure of $\alpha-\mathrm{Ni}(\mathrm{OH})_{2}$, no obvious change can be observed in the X-ray diffraction spectrum, indicating $\mathrm{Ni}_{0.75} \mathrm{~V}_{0.25}-\mathrm{LDH}$ is the isomorphous compound as $\alpha-\mathrm{Ni}(\mathrm{OH})_{2}$ with the layered structure. The X-ray diffraction pattern of prepared bare V-based hydroxide without $\mathrm{Ni}$ source (Supplementary Fig. 1) shows very low crystallinity that is significantly different from those of the above Ni-based materials. Figure 1b-d shows the Ni $2 p, \mathrm{~V} 2 p$ and $\mathrm{O} 1 s$ $\mathrm{X}$-ray photoelectron spectroscopy (XPS) core-level spectra of the $\mathrm{Ni}_{0.75} \mathrm{~V}_{0.25}$-LDH powder. The Ni $2 p$ spectrum presents two main structures, resulting from the spin-orbit splitting of the $p$ orbital that are assigned as $\mathrm{Ni} 2 p_{3 / 2}(850-870 \mathrm{eV}$ region $)$ and $\mathrm{Ni} 2 p_{1 / 2}$ $(870-890 \mathrm{eV}$ region). The binding energy difference between the $3 / 2$ and $1 / 2$ components is $\sim 17.4 \mathrm{eV}$. Ni $2 p_{3 / 2}$ presents a main peak at $\sim 855.4 \mathrm{eV}$ with an intense satellite structure at $\sim 861.2 \mathrm{eV},\left(\sim 872.8\right.$ and $\sim 879.6 \mathrm{eV}$, respectively, for $\left.\mathrm{Ni2} p_{1 / 2}\right)$, this signature is characteristic of $\mathrm{Ni}^{2}+$ (refs 18-21). The spectra of $\mathrm{O} 1 s$ and $\mathrm{V} 2 p$ are presented in Fig. 1c, the $\mathrm{O} 1 s$ signal originates from $\mathrm{Ni}_{0.75} \mathrm{~V}_{0.25}-\mathrm{LDH}$, but its main contributions is from the fluorine doped tin oxide (FTO) glass substrate used with an O1s-binding energy $\sim 530 \mathrm{eV}$. The V $2 p$ core-level spectrum is also decomposed into V $2 p_{3 / 2}$ and V $2 p_{1 / 2}$ due to the spin-orbit splitting that are separated by $\sim 7.5 \mathrm{eV}$. A closer view on the $\mathrm{V} 2 p_{3 / 2}$ region is shown in Fig. 1d. Three components can be distinguished at $\sim 515.4 \mathrm{eV}$ (in blue), $\sim 516.3 \mathrm{eV}$ (in light grey) and $\sim 517.5 \mathrm{eV}$ (in grey) and are in good agreement with respectively $\mathrm{V}^{3+}, \mathrm{V}^{4+}$ and $\mathrm{V}^{5+}(\mathrm{refs} 22-24)$. This result indicates that $\mathrm{V}^{3+}$ was partially oxidized by oxygen to $\mathrm{V}^{4+}$ and $\mathrm{V}^{5+}$ during the synthesis.

Typical transmission electron microscopy (TEM) images of $\alpha-\mathrm{Ni}(\mathrm{OH})_{2}$ and $\mathrm{Ni}_{0.75} \mathrm{~V}_{0.25}-\mathrm{LDH}$ are shown in Fig. 2. Interestingly, as shown in Fig. 2a,b, the pure $\alpha-\mathrm{Ni}(\mathrm{OH})_{2}$ shows a narrow nanosheet morphology with the size of few tens of nanometre. Aggregated by these nanosheet crystals, a porous sphere structure with the diameter of few micrometres was obtained, as observed by scanning electron microscopy (SEM; Supplementary Fig. 2a). After adding the vanadium source to the initial solution for hydrothermal reaction, $\mathrm{Ni}_{0.75} \mathrm{~V}_{0.25}$ - $\mathrm{LDH}$ presents a threedimensional morphology assembled by ultrathin nanosheets as shown in Fig. 2c,d. Selected area electron diffraction pattern in the inset of Fig. $2 \mathrm{~d}$ confirms the hexagonal phase of $\mathrm{Ni}_{0.75} \mathrm{~V}_{0.25}$ $\mathrm{LDH}$. The atomic force microscopy (AFM) and height profile of $\mathrm{Ni}_{0.75} \mathrm{~V}_{0.25}$-LDH in Fig. 2e,f show that the nanosheet is ultrathin with thickness of $\sim 0.9 \mathrm{~nm}$, indicating the obtained nanosheet is monolayered. To make a comparison, $\mathrm{Ni}_{0.75} \mathrm{Fe}_{0.25}-\mathrm{LDH}$ was also prepared by a similar protocol in the literature ${ }^{25}$ and the SEM image of the products obtained is shown in Supplementary Fig. $2 \mathrm{~b}$ and c. Some large aggregation plates in $\mathrm{Ni}_{0.75} \mathrm{Fe}_{0.25}-\mathrm{LDH}$ can be observed, showing that the size of aggregations by nanosheets in $\mathrm{Ni}_{0.75} \mathrm{Fe}_{0.25}$-LDH is bigger than $\mathrm{Ni}_{0.75} \mathrm{~V}_{0.25}$ - LDH. However, the TEM, AFM images and height profile of $\mathrm{Ni}_{0.75} \mathrm{Fe}_{0.25}-\mathrm{LDH}$ in Supplementary Fig. 2d-f exhibit that the nanosheet of $\mathrm{Ni}_{0.75} \mathrm{Fe}_{0.25}$-LDH is also ultrathin with thickness of $\sim 1.2 \mathrm{~nm}$. Meanwhile, differing from the above nanosheet-based structure, the bare V-based and Fe-based hydroxides $(\beta-\mathrm{FeOOH})$ without Ni content show mainly 'nanostick' morphologies after the hydrothermal processes (Supplementary Fig. 3).

Oxygen evolution catalysis. It is known that the composition can affect the water oxidation performance of the catalysts significantly. First, we investigated the electrocatalytic activities of $\mathrm{NiV}-\mathrm{LDHs}$ and $\mathrm{NiFe}-\mathrm{LDH}$ on glassy carbon (GC) electrodes with different $\mathrm{Ni}$ content to optimize the composition (the measurements were carried out without ohmic-drop correction unless noted otherwise). All the amount of catalyst loadings on GC electrodes were $0.143 \mathrm{mg} \mathrm{cm}^{-2}$. As shown in Supplementary Fig. 4, the $\mathrm{Ni}$ content plays an essential role for the catalytic activity in this study (the electrocatalytic activities of pure $\mathrm{Ni}(\mathrm{OH})_{2}$, bare V-based and Fe-based hydroxides are very low, so they are not shown here for clarity). When the molar ratio of $\mathrm{Ni} / \mathrm{X}(\mathrm{X}=\mathrm{V}$ or $\mathrm{Fe})$ is $3: 1$, that is, $\mathrm{Ni}_{0.75} \mathrm{~V}_{0.25}-\mathrm{LDH}$ and $\mathrm{Ni}_{0.75} \mathrm{Fe}_{0.25}-\mathrm{LDH}$, the best water oxidation performances are 

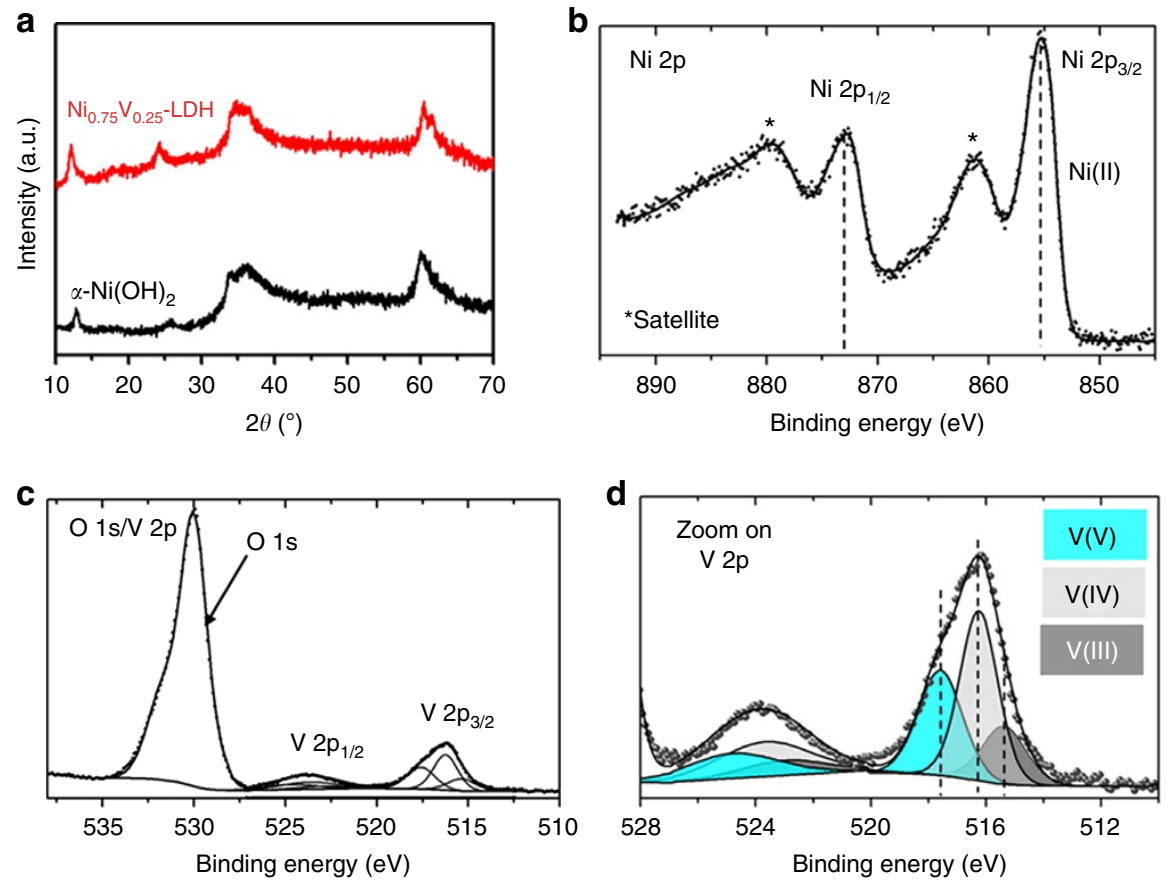

Figure 1 | X-ray diffraction and XPS. (a) X-ray diffraction patterns of $\alpha-\mathrm{Ni}(\mathrm{OH})_{2}$ and $\mathrm{Ni}_{0.75} \mathrm{~V}_{0.25}-\mathrm{LDH}$. XPS measurements $(h v=1,486.6 \mathrm{eV})$ on the $\mathrm{Ni}_{0.75} \mathrm{~V}_{0.25}-\mathrm{LDH}$ powder deposited on a FTO conductive glass: (b) Ni $2 p$ (c) $\mathrm{O} 1 \mathrm{~s}$ and $\mathrm{V} 2 p$ core-level spectra, and (d) zoom on the $\vee 2 p$ core-level spectrum.

achieved with the highest catalytic current density (Supplementary Fig. 4a-c) and turnover frequency (TOF) (Supplementary Fig. 4d), and the lowest required overpotential (Supplementary Fig. 4e) in NiV-LDH and NiFe-LDH series, respectively (note that for $\mathrm{NiFe}-\mathrm{LDH}$, this optimized molar ratio of $\mathrm{Ni} / \mathrm{Fe}$ is in a good agreement with the literature reported previously $\left.{ }^{6}\right)$. Either a lower or higher mole ratio of the two metal elements will decrease the catalytic performances of LDHs. The atomic percentage of $\mathrm{Ni}, \mathrm{V}$ and $\mathrm{Fe}$ in $\mathrm{Ni}_{0.75} \mathrm{~V}_{0.25} \mathrm{LDH}$ and $\mathrm{Ni}_{0.75} \mathrm{Fe}_{0.25}-\mathrm{LDH}$ has been measured by energy-dispersive X-ray spectroscopy (EDS; Supplementary Fig. 5), showing the molar ratios of Ni/V (3.29) and $\mathrm{Ni} / \mathrm{Fe}(2.93)$ are close to $3: 1$ that was used in the corresponding solution stoichiometries. The catalytic performances of $\mathrm{Ni}_{0.75} \mathrm{~V}_{0.25}-\mathrm{LDH}$ and $\mathrm{Ni}_{0.75} \mathrm{Fe}_{0.25}-\mathrm{LDH}$ are very reproducible (Supplementary Fig. 6) and compared in Fig. 3. A sharp onset catalytic current density can be observed at low overpotential $\eta \sim 250$ and $300 \mathrm{mV}$ for $\mathrm{Ni}_{0.75} \mathrm{~V}_{0.25}-\mathrm{LDH}$ and $\mathrm{Ni}_{0.75} \mathrm{Fe}_{0.25}-\mathrm{LDH}$, respectively. It is apparent that $\mathrm{Ni}_{0.75} \mathrm{~V}_{0.25^{-}}$ LDH exhibits a better catalytic activity than $\mathrm{Ni}_{0.75} \mathrm{Fe}_{0.25}$ - $\mathrm{LDH}$, suggesting that substituting Fe entirely by $\mathrm{V}$ in Ni-based LDH can improve the water oxidation performance in our case. The improved catalytic activity of $\mathrm{Ni}_{0.75} \mathrm{~V}_{0.25}-\mathrm{LDH}$ is not only shown via the higher catalytic current density of linear scan voltammogram (LSV) curves, but also reflected in its lower Tafel slope (Fig. $3 \mathrm{~b}$ ). $\mathrm{Ni}_{0.75} \mathrm{~V}_{0.25}$-LDH catalyst exhibits a Tafel slope of $\sim 50 \mathrm{mV} \mathrm{dec}^{-1}$, which is smaller than that of $\mathrm{Ni}_{0.75} \mathrm{Fe}_{0.25}$ - $\mathrm{LDH}$ catalyst $\left(\sim 64 \mathrm{mV} \mathrm{dec}{ }^{-1}\right)$. Tafel slopes can be influenced by mass transport and electron transport ${ }^{26,27}$. Different scan rate ranging from 1 to $5 \mathrm{mV} \mathrm{s}^{-1}$ for LSV have been done, which resulted in negligible change of current densities for $\mathrm{Ni}_{0.75} \mathrm{Fe}_{0.25}-\mathrm{LDH}$ and $\mathrm{Ni}_{0.75} \mathrm{~V}_{0.25}-\mathrm{LDH}$ catalysts, indicating sufficiently fast mass transport for both $\mathrm{LDHs}^{26,27}$. Therefore, it is reasonable to conclude that the lower Tafel slope of $\mathrm{Ni}_{0.75} \mathrm{~V}_{0.25}-\mathrm{LDH}$ is likely ascribed to the facile electron transport through the layers of the catalyst.

At $\eta$ of $350 \mathrm{mV}, \mathrm{Ni}_{0.75} \mathrm{~V}_{0.25}-\mathrm{LDH}$ can achieve current density of $27.0 \pm 1.6 \mathrm{~mA} \mathrm{~cm}^{-2}$, which is more than twice higher than the one of $\mathrm{Ni}_{0.75} \mathrm{Fe}_{0.25}$-LDH $\left(11.7 \pm 1.5 \mathrm{~mA} \mathrm{~cm}^{-2}\right)$. TOF was also calculated at an overpotential of $350 \mathrm{mV}$ in $1 \mathrm{M} \mathrm{KOH}$, assuming all the metal sites were electrochemically active in the water oxidation reaction. $\mathrm{Ni}_{0.75} \mathrm{~V}_{0.25} \mathrm{LDH}$ also shows the better TOF of $0.054 \pm 0.003 \mathrm{~s}^{-1}$ compare with $0.021 \pm 0.003 \mathrm{~s}^{-1}$ for $\mathrm{Ni}_{0.75} \mathrm{Fe}_{0.25}$ - $\mathrm{LDH}$. It is worth noting that the above TOFs in this study are obviously underestimated, since some of the metal sites are electrochemically non-accessible. Meanwhile, the overpotential $\eta$ required to achieve $10 \mathrm{~mA} \mathrm{~cm}^{-2}$ current density, which is approximately the current expected at the anode in a $10 \%$ efficient solar water splitting device under 1-sun illumination ${ }^{28}$, was also evaluated. $\mathrm{Ni}_{0.75} \mathrm{Fe}_{0.25}-\mathrm{LDH}$ and $\mathrm{Ni}_{0.75} \mathrm{~V}_{0.25}$ - LDH show required overpotential $0.347 \pm 0.002$ and $0.318 \pm 0.003 \mathrm{~V}$, respectively, exhibiting the lower required overpotential of $\mathrm{Ni}_{0.75} \mathrm{~V}_{0.25}-\mathrm{LDH}$.

In addition, we compared the durability of $\mathrm{Ni}_{0.75} \mathrm{Fe}_{0.25}-\mathrm{LDH}$ and $\mathrm{Ni}_{0.75} \mathrm{~V}_{0.25} \mathrm{LDH}$ in $1 \mathrm{M} \mathrm{KOH}$ (Fig. 4). When biased galvanostatically at $10 \mathrm{~mA} \mathrm{~cm}{ }^{-2}$, both of $\mathrm{Ni}_{0.75} \mathrm{Fe}_{0.25}$ - $\mathrm{LDH}$ and $\mathrm{Ni}_{0.75} \mathrm{~V}_{0.25}-\mathrm{LDH}$ electrodes show considerable stability, the slightly decrease of the required potential for $\mathrm{Ni}_{0.75} \mathrm{~V}_{0.25}-\mathrm{LDH}$ electrode may be due to the amorphazation during the anodic conditioning process ${ }^{26,29}$. Obviously, $\mathrm{Ni}_{0.75} \mathrm{~V}_{0.25}$ - $\mathrm{LDH}$ electrode requires less overpotential than $\mathrm{Ni}_{0.75} \mathrm{Fe}_{0.25}-\mathrm{LDH}$, showing its comparable stability and catalytic performance to $\mathrm{Ni}_{0.75} \mathrm{Fe}_{0.25}$ - $\mathrm{LDH}$ for water splitting.

\section{Discussion}

To understand the reason behind the high catalytic performance of $\mathrm{Ni}_{0.75} \mathrm{~V}_{0.25}-\mathrm{LDH}$ for water splitting, electrochemical active surface areas (ECSA) of $\mathrm{Ni}_{0.75} \mathrm{~V}_{0.25}-\mathrm{LDH}$ and $\mathrm{Ni}_{0.75} \mathrm{Fe}_{0.25}-\mathrm{LDH}$ were obtained from cyclic voltammetry (CV) curves in $1 \mathrm{M} \mathrm{KOH}$ and compared. Figure 5a shows typical CV curves of $\mathrm{Ni}_{0.75}$ $\mathrm{V}_{0.25}$-LDH with different scan rates. By plotting the $\Delta J=\left(J_{\mathrm{a}}-J_{\mathrm{c}}\right)$ at $0.25 \mathrm{~V}$ versus $\mathrm{Ag} / \mathrm{AgCl}$ against the scan rate, the linear slope that is twice the double layer capacitance $\left(C_{\mathrm{dl}}\right)$ can be obtained, and is normally used to represent the corresponding ECSA $\mathrm{E}^{1,9,11,26}$. 
a

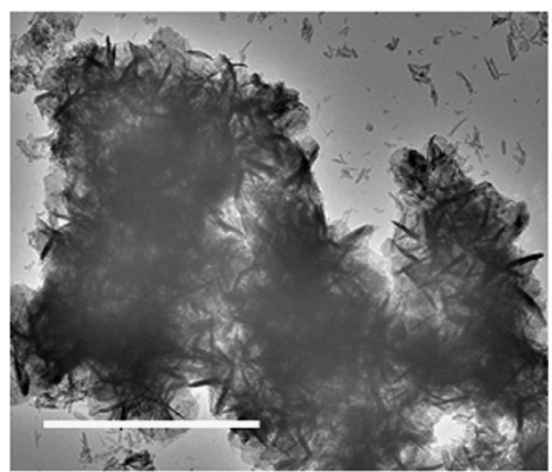

C

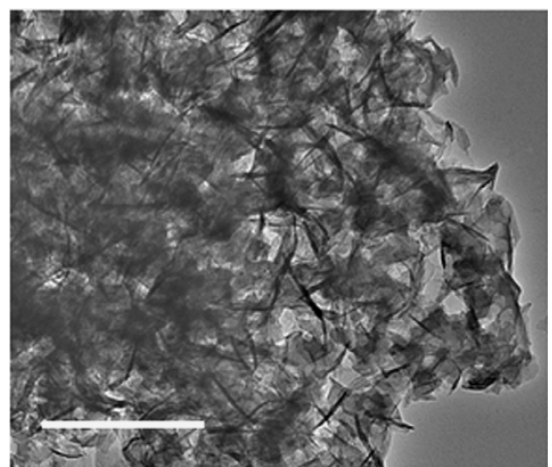

b

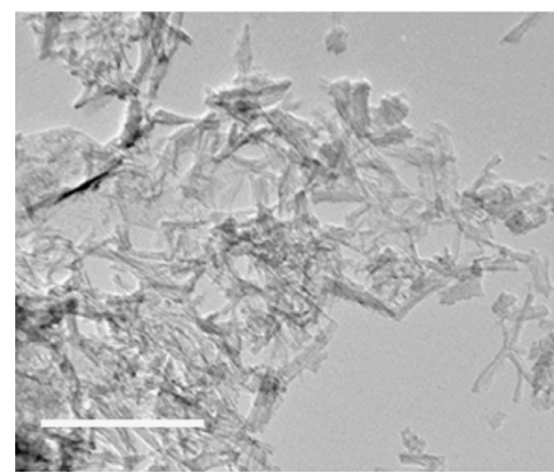

d

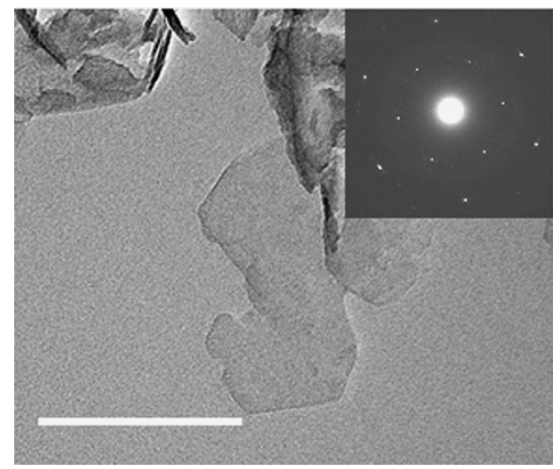

e

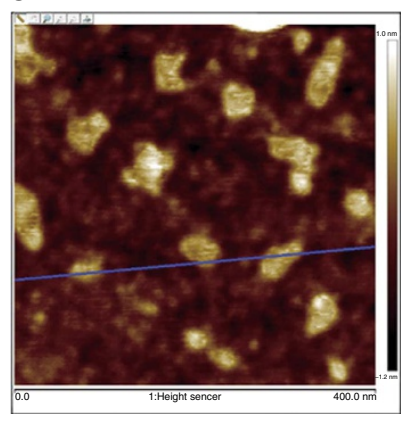

$\mathbf{f}$

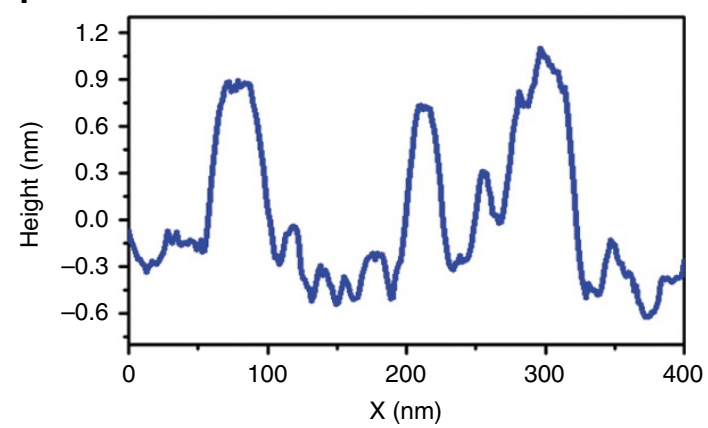

Figure 2 | TEM and AFM. (a,b) TEM images of $\alpha-\mathrm{Ni}(\mathrm{OH})_{2}$. Scale bar, $1 \mu \mathrm{m}(\mathbf{a}) ; 200 \mathrm{~nm}(\mathbf{b}) ;(\mathbf{c}, \mathbf{d})$ TEM images of $\mathrm{Ni}_{0.75} \mathrm{~V}_{0.25}-\mathrm{LDH}$ (inset of d: selected area electron diffraction pattern). Scale bar, $200 \mathrm{~nm}$ (c); $100 \mathrm{~nm}$ (d); (e) AFM image and (f) height profile of $\mathrm{Ni}_{0.75} \mathrm{~V}_{0.25}-\mathrm{LDH}$ nanosheets.

Active surface area is a very important factor for catalysts in water oxidation reaction, as it is well known that an increase of active surface area often leads to enhancement of the catalytic activity. The linear slope (ECSA) of $\mathrm{Ni}_{0.75} \mathrm{Fe}_{0.25}-\mathrm{LDH}$ is $0.199 \pm 0.018 \mathrm{mF} \mathrm{cm}^{-2}$, while $\mathrm{Ni}_{0.75} \mathrm{~V}_{0.25} \mathrm{LDH}$ has a higher linear slope of $0.270 \pm 0.030 \mathrm{mF} \mathrm{cm}^{-2}$, which means $\mathrm{Ni}_{0.75}$ $\mathrm{V}_{0.25}-\mathrm{LDH}$ has a more electroactive surface than $\mathrm{Ni}_{0.75} \mathrm{Fe}_{0.25}-\mathrm{LDH}$ (Fig. 5b). The bigger ECSA should be attributed to the smaller size of aggregations by nanosheets in $\mathrm{Ni}_{0.75} \mathrm{~V}_{0.25}-\mathrm{LDH}$ (as shown in Supplementary Fig. 2). This can contribute to partial enhancement of water oxidation reaction presented here. Nevertheless, it is important to note that comparing to $\mathrm{Ni}_{0.75} \mathrm{Fe}_{0.25}-\mathrm{LDH}, \mathrm{Ni}_{0.75} \mathrm{~V}_{0.25}-\mathrm{LDH}$ has just slightly $\sim 36 \%$ higher ECSA due to the similar nanostructure, with such small increase of ECSA, more than twofold of current density at $\eta=350 \mathrm{mV}$ can be achieved. This improvement of the catalytic activity cannot be merely ascribed to the slightly increased surface area of the catalysts. This result suggests that $\mathrm{Ni}_{0.75} \mathrm{~V}_{0.25}-\mathrm{LDH}$ may have higher intrinsic catalytic activity for water oxidation reaction.
To verify this point, the ECSAs of NiV-LDH with different $\mathrm{Ni}$ content were further examined in details, as shown in Fig. 6a-c. The slopes (ECSA) of $\mathrm{Ni}_{0.25} \mathrm{~V}_{0.75^{-}}, \mathrm{Ni}_{0.5} \mathrm{~V}_{0.5^{-}}, \mathrm{Ni}_{0.75} \mathrm{~V}_{0.25^{-}}$and $\mathrm{Ni}_{0.83} \mathrm{~V}_{0.17}-\mathrm{LDH}$ electrodes were $0.123 \pm 0.009,0.166 \pm 0.012$, $0.270 \pm 0.030$ and $0.144 \pm 0.015 \mathrm{mF} \mathrm{cm}^{-2}$, respectively, in Fig. 6a. Obviously, the largest ECSA can be achieved when the Ni content was 0.75 in NiV-LDHs, as shown in Fig. 6 b as well. The relationship of ECSA with the current density of different $\mathrm{NiV}$-LDHs is exhibited in Fig. 6c. One can see that the current density of NiV-LDH increases with ECSA, further confirming the active surface area of catalyst is an important contributor for the enhancement of water oxidation reaction. However, investigating this result carefully, the ECSA has more than twofold increase from $\sim 0.123$ to $0.270 \mathrm{mF} \mathrm{cm}^{-2}$, while the corresponding current density increases from $\sim 4.0$ to $27.0 \mathrm{~mA} \mathrm{~cm}^{-2}$, showing significantly almost seven times improvement. This is a strong clue that incorporating $\mathrm{V}$ into $\mathrm{Ni}$ hydroxide can not only change the active surface area, but also enhance the intrinsic catalytic property. As a comparison, we also investigated current density-dependent ECSA of different NiFe-LDHs in Fig. 6d. 
a
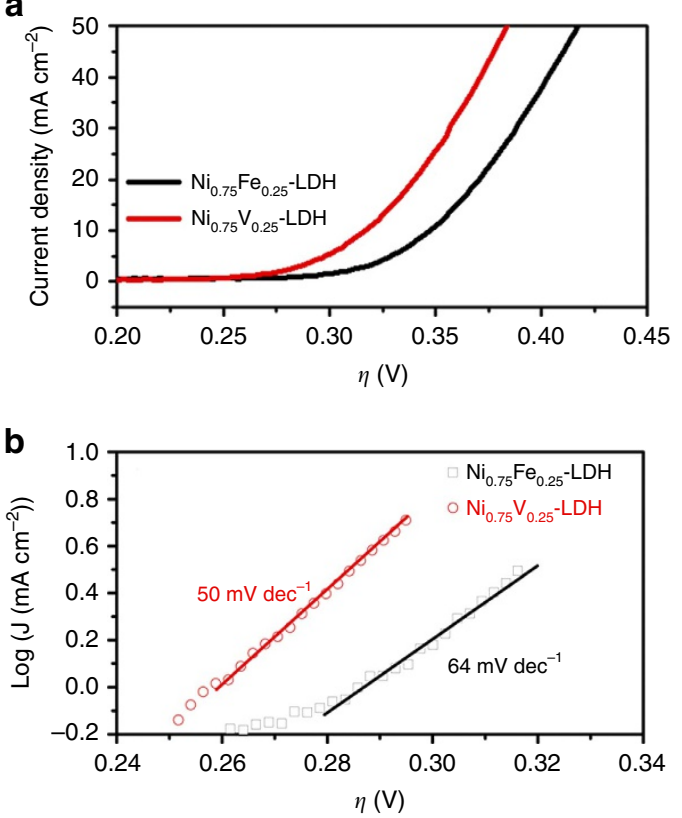

Figure 3 | Linear scan voltammogram (LSV) curves and Tafel plots. (a) LSV curves and (b) Tafel plots (with ohmic-drop correction) of $\mathrm{Ni}_{0.75} \mathrm{Fe}_{0.25}-\mathrm{LDH}$ and $\mathrm{Ni}_{0.75} \mathrm{~V}_{0.25}-\mathrm{LDH}$.

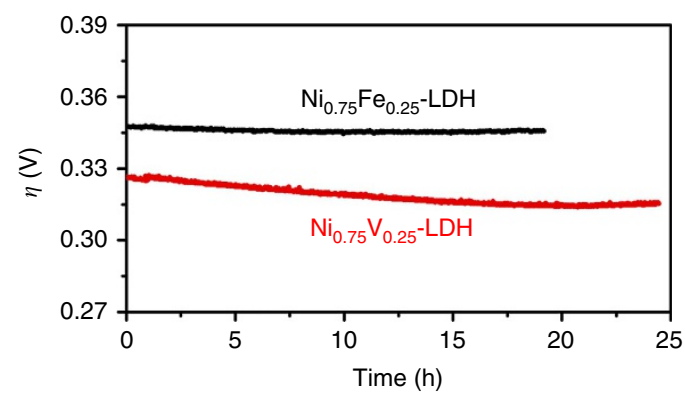

Figure 4 | Long-term stability. Chronopotentiometry curves at current density of $10 \mathrm{~mA} \mathrm{~cm}^{-2}$ of $\mathrm{Ni}_{0.75} \mathrm{Fe}_{0.25}-\mathrm{LDH}$ and $\mathrm{Ni}_{0.75} \mathrm{~V}_{0.25}-\mathrm{LDH}$.
For NiFe-LDHs, the current density increases with ECSA as well; however, comparing with the significantly enhanced current density of NiV-LDH, the current density of NiFe-LDH just almost linearly increases to 1.6-fold (from $\sim 7.45$ to $11.76 \mathrm{~mA} \mathrm{~cm}^{-2}$ ) with 1.3-fold increase of ECSA (from $\sim 0.157$ to $0.199 \mathrm{mF} \mathrm{cm}^{-2}$ ). This linear correlation indeed indicates that the improvement of catalytic activity of NiFe-LDHs is mainly due to the increase of actively accessible surface area. We attempted to make a comparison of the catalytic activities between NiFe-LDH and NiV-LDH with the same ECSA value. The linear correlation in Fig. $6 \mathrm{~d}$ for NiFe-LDH is used to predict the current density of $\mathrm{NiFe}-\mathrm{LDH}$ with $0.270 \mathrm{mF} \mathrm{cm}^{-2}$ of ECSA (the blue solid square in Fig. 6d), which is supposed to have the same ECSA with $\mathrm{Ni}_{0.75} \mathrm{~V}_{0.25}$-LDH catalyst (the red solid circle in Fig. $6 \mathrm{~d}$ ). The expected current density of NiFe-LDH described above $\left(\sim 20.0 \mathrm{mAcm}^{-2}\right)$ is still lower than $\mathrm{Ni}_{0.75} \mathrm{~V}_{0.25}-\mathrm{LDH}$ $\left(\sim 27.0 \mathrm{~mA} \mathrm{~cm}^{-2}\right)$, although they have been estimated to have the same ECSA value. These results suggest in addition to the increased accessible surface area, probably the $\mathrm{V}$ in the Ni-based LDHs can also lead to the increased intrinsic catalytic activity than NiFe-LDHs in our case.

Although it is difficult to correctly normalize the catalytic current to the number of active sites in the $\mathrm{LDH}$ electrocatalysts to compare the intrinsic catalytic performances accurately, the kinetic parameters of the Tafel slope and onset potential can be selected to reflect the intrinsic activity of catalysts ${ }^{30,31}$. Thus, we investigated the Tafel slopes and onset potentials of $\mathrm{Ni}_{0.75} \mathrm{Fe}_{0.25}-\mathrm{LDH}$ and $\mathrm{Ni}_{0.75} \mathrm{~V}_{0.25}-\mathrm{LDH}$ in Fig. 3 again. The Tafel slope is only affected by the kinetics of the reaction, which involves the type of active sites but not its quantity, surface area, morphology or electrical resistance ${ }^{30}$. Therefore, the lower Tafel slope of $\mathrm{Ni}_{0.75} \mathrm{~V}_{0.25} \mathrm{LDH}\left(\sim 50 \mathrm{mV} \mathrm{dec}^{-1}\right)$ than that of $\mathrm{Ni}_{0.75} \mathrm{Fe}_{0.25}-\mathrm{LDH}\left(\sim 64 \mathrm{mV} \mathrm{dec}{ }^{-1}\right)$ indicates the higher catalytic activity and superior type of the active sites in $\mathrm{Ni}_{0.75} \mathrm{~V}_{0.25}-\mathrm{LDH}$. In addition, $\mathrm{Ni}_{0.75} \mathrm{~V}_{0.25}-\mathrm{LDH}$ also shows lower onset potential $\left(\sim 250 \mathrm{mV}\right.$ overpotential) than that of $\mathrm{Ni}_{0.75} \mathrm{Fe}_{0.25}-\mathrm{LDH}$ ( $\sim 300 \mathrm{mV}$ overpotential), implying the facile kinetics of $\mathrm{Ni}_{0.75} \mathrm{~V}_{0.25}-\mathrm{LDH}$ for the water oxidation reaction, which is consistent with the Tafel slope investigation. These results indicate that $\mathrm{Ni}_{0.75} \mathrm{~V}_{0.25} \mathrm{LDH}$ possesses superior intrinsic catalytic activity in our case.
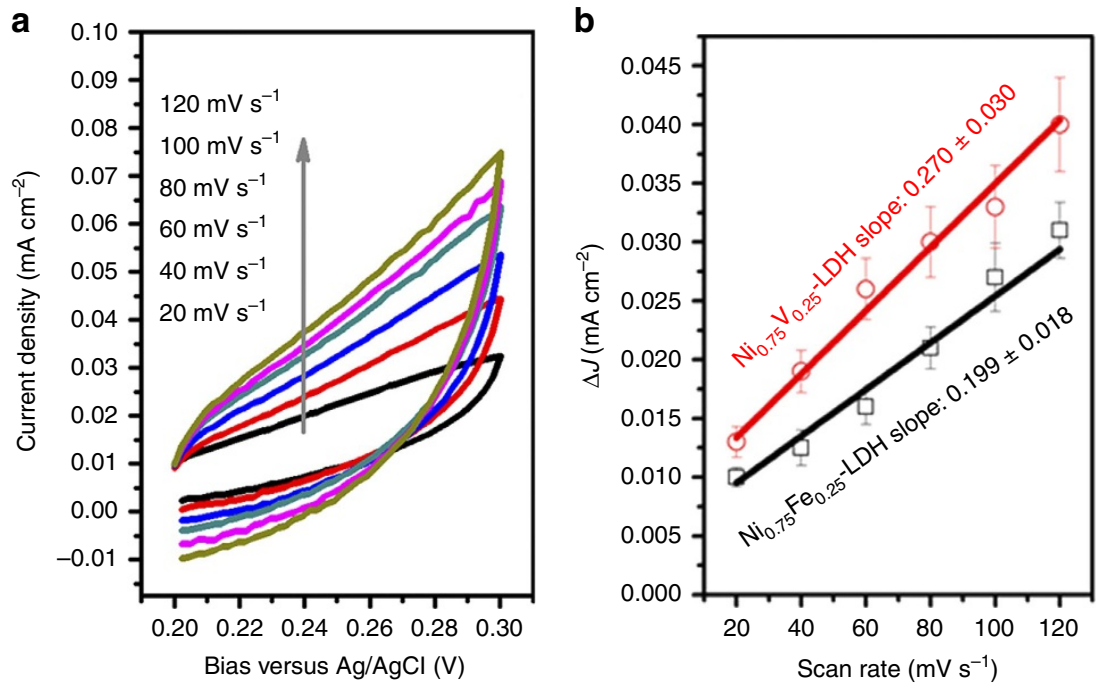

Figure 5 | ECSA of $\mathbf{N i}_{\mathbf{0 . 7 5}} \mathbf{F e}_{\mathbf{0 . 2 5}}-\mathbf{L D H}$ and $\mathbf{N i}_{\mathbf{0 . 7 5}} \mathbf{V}_{\mathbf{0 . 2 5}}$ - LDH. (a) Typical cyclic voltammetry curves of $\mathrm{Ni}_{0.75} \mathrm{~V}_{0.25}-\mathrm{LDH}$ electrode in $1 \mathrm{M} \mathrm{KOH}$ with different scan rates; $(\mathbf{b}) \Delta \mathrm{J}\left(=J_{\mathrm{a}}-J_{\mathrm{c}}\right)$ of $\mathrm{Ni}_{0.75} \mathrm{Fe}_{0.25}-\mathrm{LDH}$ and $\mathrm{Ni}_{0.75} \mathrm{~V}_{0.25}-\mathrm{LDH}$ plotted against scan rates. All the error bars represent the s.d.'s of three replicate measurements. The slopes $\left(2 \mathrm{C}_{\mathrm{dl}}\right)$ were used to represent ECSA. The unit of slopes is $\mathrm{mF} \mathrm{cm}^{-2}$. 

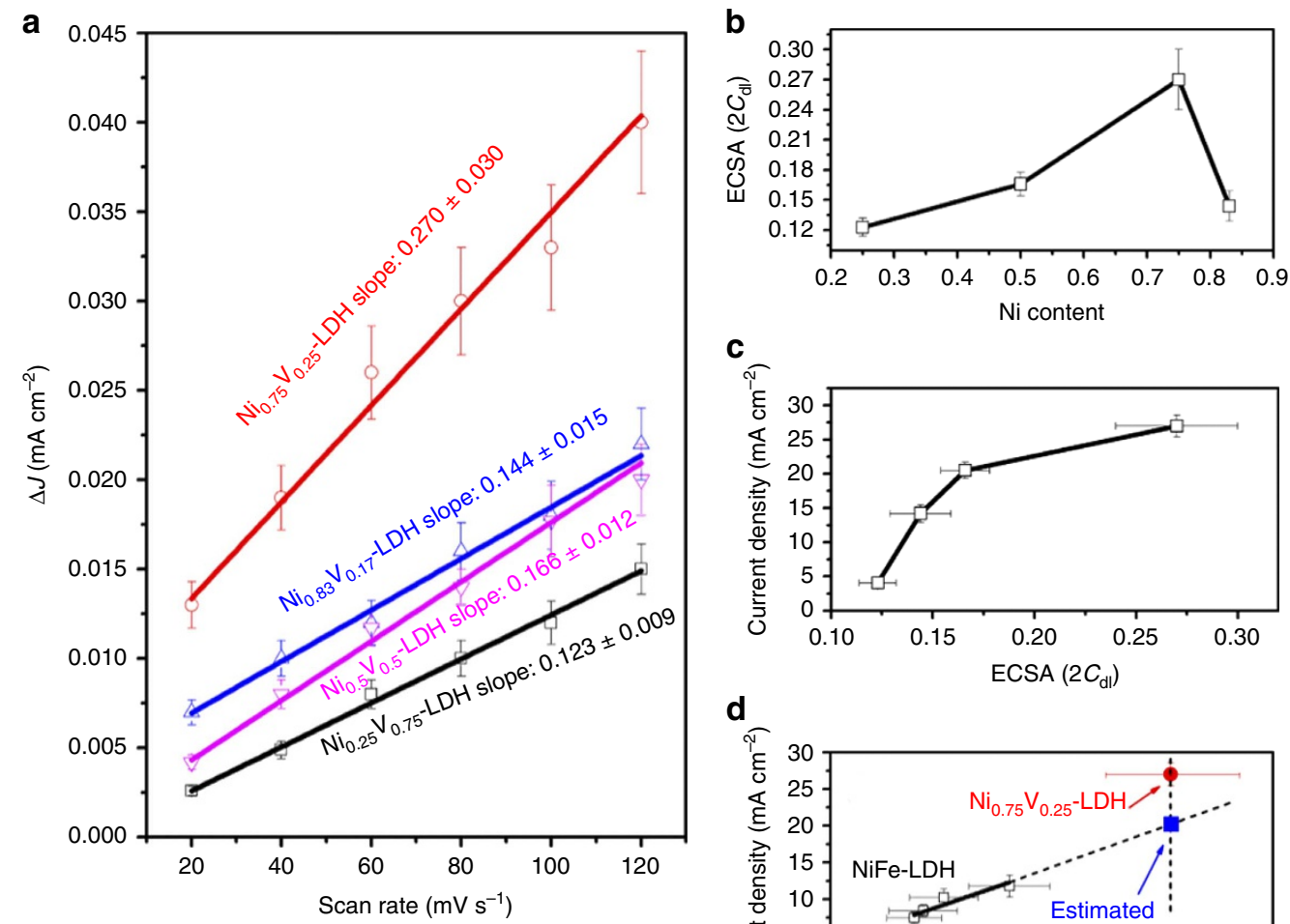

C
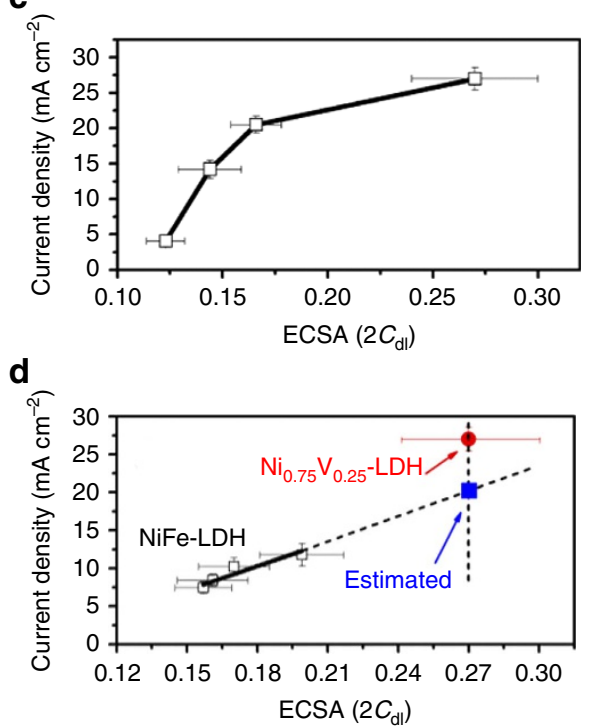

Figure 6 I ECSA of LDHs. (a) $\Delta J\left(=J_{\mathrm{a}}-J_{\mathrm{c}}\right)$ of NiV-LDH with different Ni contents plotted against scan rates. The unit of slopes is $\mathrm{mF} \mathrm{cm}^{-2}$; (b) ECSA $\left(2 C_{d 1}\right)$ of NiV-LDH with different $\mathrm{Ni}$ contents; (c) current density at $350 \mathrm{mV}$ overpotential plotted against ECSA (2C $\left.\mathrm{C}_{\mathrm{dl}}\right)$ of NiV-LDH with different Ni contents; and (d) current density at $350 \mathrm{mV}$ overpotential plotted against ECSA (2 $\mathrm{C}_{\mathrm{dl}}$ ) of NiFe-LDH with different Ni contents (black open squares), estimated the activity of $\mathrm{NiFe}-\mathrm{LDH}$ (blue solid square) with the same ECSA of $\mathrm{Ni}_{0.75} \mathrm{~V}_{0.25}-\mathrm{LDH}$ (red solid circle). All the error bars represent the s.d.'s of three replicate measurements.

The higher intrinsic catalytic activity of $\mathrm{Ni}_{0.75} \mathrm{~V}_{0.25}-\mathrm{LDH}$ may be due to the higher conductivity than $\mathrm{Ni}_{0.75} \mathrm{Fe}_{0.25}-\mathrm{LDH}$. To test the conductivity, electrochemical impedance spectroscopies (EIS) of $\mathrm{Ni}_{0.75} \mathrm{Fe}_{0.25}-\mathrm{LDH}$ and $\mathrm{Ni}_{0.75} \mathrm{~V}_{0.25}-\mathrm{LDH}$ electrodes were carried out in the three-electrode configuration in $1 \mathrm{M} \mathrm{KOH}$. The Nyquist diagrams of both electrodes show an apparent semicircle in the high frequency range (Fig. 7a), which should be mainly associated with charge transfer resistance $\left(R_{\mathrm{ct}}\right)$ in the LDH catalysts $^{32,33}$. The diameter of the semicircle in Nyquist diagram of $\mathrm{Ni}_{0.75} \mathrm{~V}_{0.25}-\mathrm{LDH}$ decreases comparing to that of $\mathrm{Ni}_{0.75} \mathrm{Fe}_{0.25}-\mathrm{LDH}$, indicating lower charge transfer resistance, that is, improved conductivity in LDH catalysts. A reported electrical analogue was used to fit the EIS data ${ }^{32}$, and the $R_{\mathrm{ct}}$ of $\mathrm{Ni}_{0.75} \mathrm{~V}_{0.25}-\mathrm{LDH}$ is estimated to be $\sim 62 \Omega \mathrm{cm}^{2}$, lower than that of $\mathrm{Ni}_{0.75} \mathrm{Fe}_{0.25}-\mathrm{LDH}\left(\sim 94 \Omega \mathrm{cm}^{2}\right)$. This is also reflected in the Bode plots in Fig. 7 b, where $\mathrm{Ni}_{0.75} \mathrm{~V}_{0.25}$ - $\mathrm{LDH}$ shows smaller resistance than $\mathrm{Ni}_{0.75} \mathrm{Fe}_{0.25}-\mathrm{LDH}$. It is known that the LDHs suffer from their low conductivity, in the current case, the higher electron conductivity of $\mathrm{Ni}_{0.75} \mathrm{~V}_{0.25}-\mathrm{LDH}$ benefits the charge transfer efficiently, which is also in a good agreement with the lower Tafel slope in Fig. 3b.

On the other hand, comparing to the relatively planar structure in $\mathrm{Ni}_{0.75} \mathrm{Fe}_{0.25}-\mathrm{LDH}$, the slightly more three-dimensional structured $\mathrm{Ni}_{0.75} \mathrm{~V}_{0.25}$ - $\mathrm{LDH}$ can expose more edges of the nanosheets to the electrolyte (see TEM images in Fig. 2c,d and Supplementary Fig. 2). The edges are expected to contain open coordination sites that can be the active sites for water oxidation. Therefore, from this point, $\mathrm{Ni}_{0.75} \mathrm{~V}_{0.25}$ - $\mathrm{LDH}$ exposes more active sites than $\mathrm{Ni}_{0.75} \mathrm{Fe}_{0.25}$-LDH in electrolyte, while maintaining a
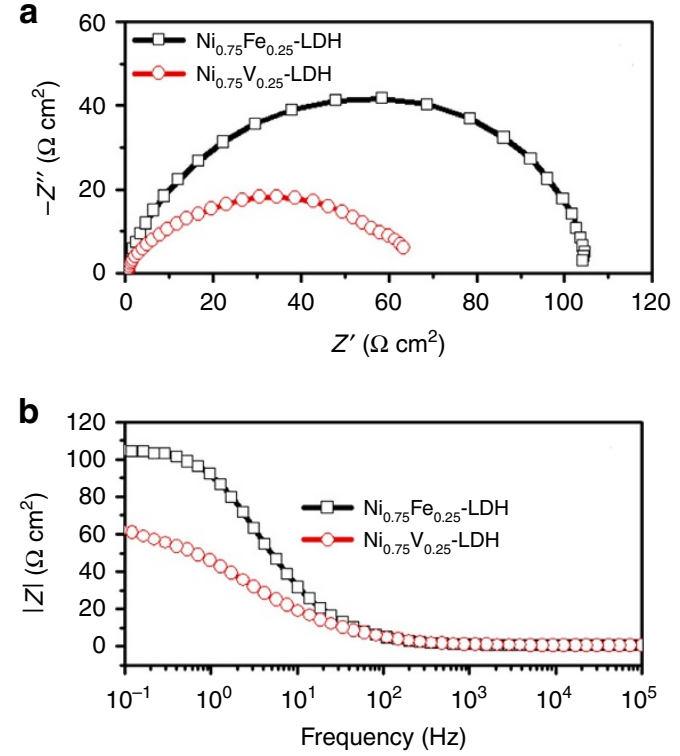

Figure 7 | EIS measurements. (a) Nyquist diagram and (b) Bode plots of $\mathrm{Ni}_{0.75} \mathrm{Fe}_{0.25}-\mathrm{LDH}$ and $\mathrm{Ni}_{0.75} \mathrm{~V}_{0.25}-\mathrm{LDH}$ with bias of $350 \mathrm{mV}$ overpotential.

similar active surface area. This may be another important factor contributing to the highly catalytic activity of $\mathrm{Ni}_{0.75} \mathrm{~V}_{0.25}$ - $\mathrm{LDH}$. Meanwhile, investigating Fig. $6 \mathrm{c}$ again, it is also noted that the increases in ECSA produce large changes in current density up to 
$\mathrm{ECSA}=0.17\left(2 C_{\mathrm{dl}}\right)$, but after that the trend is much less pronounced. This change of trend of the activity dependent on ECSA for NiV-LDHs indicates that there should be other factors that can influence the activity of NiV-LDHs besides ECSA. It was reported that the catalytic performance of the layered catalyst for water splitting more strongly depends on the edge-state length than ECSA. The catalytic activity can be linear to the edge-state length ${ }^{34}$. Therefore, as shown in Fig. 6c, a plausible explanation is that it can be speculated that at small ECSA $(<0.17$ in our case), the active sites on the edge-state length can be exposed to the electrolyte sufficiently, increasing with ECSA, and dominate the catalytic activity, so the modest increases in ECSA can produce large changes in current density by the edge-state length. However, when the ECSA increases to a large value, due to the aggregation, ESCA will cover numerous edges of the nanosheets from the electrolyte, which makes ECSA show more significant effect than the edge-state length, resulting in a slower increase rate. This result also indicates the important role that the edge state of LDHs plays in the catalytic activity. More investigations into the detailed mechanism are in progress.

To further understand the advantages of $\mathrm{Ni}_{0.75} \mathrm{~V}_{0.25}-\mathrm{LDH}$, density functional theory (DFT) calculations were performed based on the following mechanism for water oxidation:

$$
\begin{gathered}
\mathrm{H}_{2} \mathrm{O}+* \rightarrow * \mathrm{OH}_{2} \\
* \mathrm{OH}_{2} \rightarrow * \mathrm{OH}+\mathrm{H}^{+}+e \\
* \mathrm{OH} \rightarrow * \mathrm{O}+\mathrm{H}^{+}+e \\
\mathrm{H}_{2} \mathrm{O}+* \mathrm{O} \rightarrow * \mathrm{OOH}+\mathrm{H}^{+}+e \\
* \mathrm{OOH} \rightarrow \mathrm{O}_{2}+*+\mathrm{H}^{+}+e
\end{gathered}
$$

Here '*' presents the adsorption site that is usually on the top of the doping element. The calculation of the reaction free energy with the zero-point energy and entropy corrections followed the same procedure in ref. 35. Reaction free energies of reaction 1-5 are denoted as $\Delta G_{1}-\Delta G_{5}, \Delta G_{5}$ is defined as $4.92 \mathrm{eV}-\Delta G_{1}-\Delta G_{2}-$ $\Delta G_{3}-\Delta G_{4}$ to avoid the calculation of the energy of $\mathrm{O}_{2}$ molecule. The overpotential $\eta$ is defined in equation (1):

$$
\eta=\max \left\{\Delta G_{2}, \Delta G_{3}, \Delta G_{4}, \Delta G_{5}\right\} / e-1.23 \mathrm{~V}
$$

The optimized structures of the intermediates in the free-energy landscape are shown in Fig. 8. The intermediate ${ }^{\star} \mathrm{OH}$ and ${ }^{\star} \mathrm{OOH}$ bind to the surface through oxygen with a single bond. The difference of their binding energies has been shown to be a constant $(3.2 \pm 0.2 \mathrm{eV})$ for various materials, such as metals and oxides $^{36}$. In our case, the constant is calculated to be $3.22 \mathrm{eV}$. Because this binding energy difference equals to the sum of the reaction free energies of reaction 3 and $4\left(\Delta G_{3}+\Delta G_{4}\right)^{35,37}$, the rate-limiting step is either the formation of ${ }^{\star} \mathrm{O}$ from ${ }^{\star} \mathrm{OH}\left(\Delta G_{3}\right)$ or formation of ${ }^{\star} \mathrm{OOH}$ from ${ }^{\star} \mathrm{O}\left(\Delta G_{4}\right)$. The calculated free-energy landscape shows that the rate-limiting step is the formation of ${ }^{\star} \mathrm{OOH}$ when the sample is doped with $\mathrm{V}$ with $\eta=0.62 \mathrm{~V}$, whereas the rate-limiting step becomes the formation of ${ }^{\star} \mathrm{O}$ when the sample is doped with $\mathrm{Fe}$ with $\eta=1.28 \mathrm{~V}$. Because $\Delta G_{3}+\Delta G_{4}=3.22 \mathrm{eV}$, the lower limit of the $\eta$ can be reached when $\Delta G_{3}=\Delta G_{4}=1 / 2 \times 3.22 \mathrm{eV}=1.61 \mathrm{eV}$ if a proper element was doped. Then $\eta=1.61-1.23=0.38 \mathrm{~V}$, which suggests it has a large space to further optimize the activity of Ni-based LDH by doping with other elements.

Besides being better than the prepared NiFe-LDH in our case, $\mathrm{Ni}_{0.75} \mathrm{~V}_{0.25}$-LDH shows superior catalytic performance than other reported LDHs as well, to the best of our knowledge. Supplementary Table 1 compares the activity of $\mathrm{Ni}_{0.75} \mathrm{~V}_{0.25}-\mathrm{LDH}$ with recently reported state-of-the-art LDH catalysts without exfoliation or coupling with other materials, which were loaded on GC electrodes for water splitting, including $\mathrm{NiFe}-, \mathrm{NiCo}-$, ZnCo-, CoCo- and MnCo-LDHs. Although the catalytic performances of $\mathrm{LDH}$ electrodes are strongly dependent on the preparation methods in literatures, to make a general overview, the current density at $350 \mathrm{mV}$ overpotential and the corresponding mass activity $\left(\mathrm{Ag}^{-1}\right)$ are still used to compare the intrinsic activities between different $\mathrm{LDH}$ catalysts. To make the comparison more reasonable, ohmic-drop correction was also performed for $\mathrm{Ni}_{0.75} \mathrm{~V}_{0.25}-\mathrm{LDH}$, as most of the literature has done (Supplementary Fig. 7) 8,9,26,29,38. In our case, without ohmicdrop correction, at $350 \mathrm{mV}$ overpotential, $\mathrm{Ni}_{0.75} \mathrm{~V}_{0.25}-\mathrm{LDH}$ can achieve $\sim 27 \mathrm{~mA} \mathrm{~cm}^{-2}$ current density with $\sim 190 \mathrm{Ag}^{-1}$ mass activity. After ohmic-drop correction, the current density and mass activity can be as high as $\sim 57 \mathrm{~mA} \mathrm{~cm}^{-2}$ and $\sim 400 \mathrm{Ag}^{-1}$, respectively. Those results are even better than some exfoliated $\mathrm{NiFe}^{-}, \mathrm{NiCo}-$ and CoCo-LDHs. It is worthy to note that $\mathrm{Ni}_{0.75} \mathrm{~V}_{0.25}-\mathrm{LDH}$ shows even higher activity than MnCo-LDH $\left(\sim 43 \mathrm{~mA} \mathrm{~cm}^{-2}\right.$ and $\left.\sim 301 \mathrm{Ag}^{-1}\right)$ before long-term anodic conditioning that was reported as one of the most active $\mathrm{LDH}$ catalyst for water oxidation ${ }^{26}$.

It is worth pointing out that although $\mathrm{Ni}_{0.75} \mathrm{~V}_{0.25}-\mathrm{LDH}$ outperforms $\mathrm{Ni}_{0.75} \mathrm{Fe}_{0.25}$-LDH in our case, we cannot claim $\mathrm{Ni}_{0.75} \mathrm{~V}_{0.25}-\mathrm{LDH}$ has higher catalytic activity than all the $\mathrm{NiFe}-\mathrm{LDH}$ s in the literature. For instance, Louie and Bell reported $\mathrm{NiFe}-\mathrm{LDH}$ that requires $<300 \mathrm{mV}$ overpotential to deliver current densities of $10 \mathrm{~mA} \mathrm{~cm}^{-2}$ with a Tafel slope of

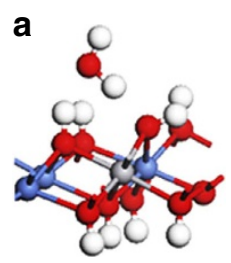

b

C

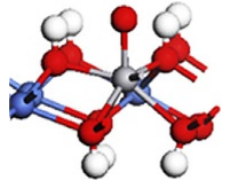

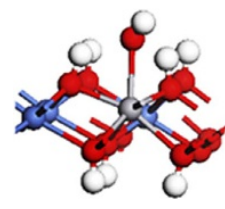

d

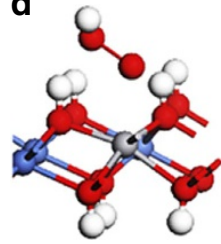

e

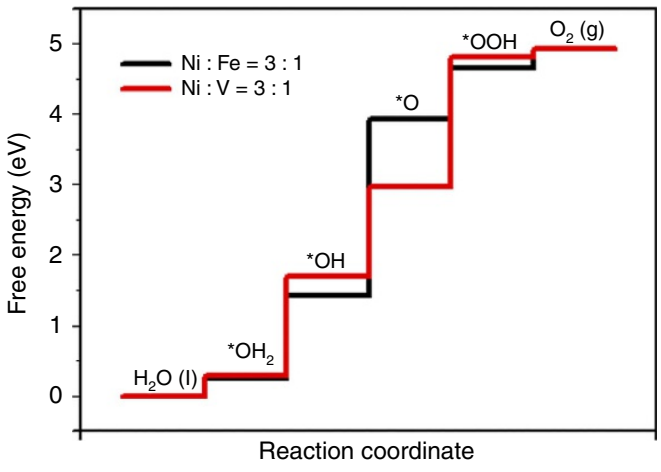

Figure 8 | DFT calculation. Adsorption geometries of the intermediates $\mathrm{H}_{2} \mathrm{O},{ }^{\star} \mathrm{OH},{ }^{\star} \mathrm{O}$ and ${ }^{\star} \mathrm{OOH}$ in $\mathbf{a}, \mathbf{b}, \mathbf{c}$ and $\mathbf{d}$, respectively. The red, blue, white, grey atoms represent the $\mathrm{O}, \mathrm{Ni}, \mathrm{H}$ and $\mathrm{V}$ atoms, respectively. The adsorption structures are similar to these when one $\mathrm{Ni}$ is substituted by Fe instead of $\mathrm{V}$; (e) the free-energy landscape. 
$\sim 40 \mathrm{mV} \mathrm{dec}^{-1} \quad$ (with ohmic-drop correction), which outperforms our $\mathrm{Ni}_{0.75} \mathrm{~V}_{0.25}-\mathrm{LDH}$ probably due to the different preparation method ${ }^{12}$. Nevertheless, from Supplementary Table 1, our $\mathrm{Ni}_{0.75} \mathrm{~V}_{0.25}-\mathrm{LDH}$ is still highly efficient among the listed catalysts, and comparable to the best-performing $\mathrm{NiFe}-\mathrm{LDHs}^{12}$, which indicates our $\mathrm{Ni}_{0.75} \mathrm{~V}_{0.25}-\mathrm{LDH}$ is one of the best water oxidation catalysts.

To confirm the $\mathrm{O}_{2}$ evolution and Faradaic efficiency of $\mathrm{Ni}_{0.75} \mathrm{~V}_{0.25}$-LDH electrode, the experimental and theoretical $\mathrm{O}_{2}$ evolution amount by $\mathrm{Ni}_{0.75} \mathrm{~V}_{0.25}-\mathrm{LDH}$ at a constant oxidative current of $1 \mathrm{~mA}$ in $1 \mathrm{M} \mathrm{KOH}$ were performed as shown in Supplementary Fig. 8. The experimental $\mathrm{O}_{2}$ evolution determined by gas chromatography exhibited $101 \pm 7 \%$ Faradaic efficiency, when the electrolysis time was $60 \mathrm{~min}$. Moreover, to further explore the highly catalytic activity of $\mathrm{Ni}_{0.75} \mathrm{~V}_{0.25}-\mathrm{LDH}$, we drop-casted $\mathrm{Ni}_{0.75} \mathrm{~V}_{0.25}$ - $\mathrm{LDH}$ suspension onto $\mathrm{Ni}$ foam as well, which can supply excellent conductivity and very high surface area for the electrode, and tested the catalytic activity of resulted electrode in $1 \mathrm{M} \mathrm{KOH}$ for water oxidation. The $\mathrm{Ni}_{0.75} \mathrm{~V}_{0.25}-\mathrm{LDH}$ on $\mathrm{Ni}$ foam exhibits the promising activity for practical applications, with $\sim 44 \mathrm{~mA} \mathrm{~cm}^{-2}$ at $350 \mathrm{mV}$ overpotential, and just $\sim 300 \mathrm{mV}$ overpotential required to reach $10 \mathrm{~mA} \mathrm{~cm}^{-2}$ (Supplementary Fig. 9) without ohmic-drop correction. Such catalytic activities of $\mathrm{Ni}_{0.75} \mathrm{~V}_{0.25}-\mathrm{LDH}$ on $\mathrm{Ni}$ foam indicate attractive prospects for large-scale and practical applications.

In summary, $\mathrm{Ni}_{0.75} \mathrm{~V}_{0.25}-\mathrm{LDH}$ has been prepared by a simple hydrothermal method, which is monolayered and shows high catalytic activity for the water oxidation reaction comparable to the best-performing NiFe-LDHs. The high intrinsic catalytic activity of $\mathrm{Ni}_{0.75} \mathrm{~V}_{0.25} \mathrm{LDH}$ is mainly due to the good conductivity, facile electron transfer and abundant active sites in the nanolayers of $\mathrm{Ni}_{0.75} \mathrm{~V}_{0.25}-\mathrm{LDH}$, showing potential to be one of the most effective Ni-based LDH electrocatalysts. Our study reveals the promising catalytic properties of vanadium incorporated Ni-based LDHs, and expands the scope of non-precious metal catalysts with the highly intrinsic activity for the water oxidation reaction.

\section{Methods \\ Preparation of NiV- and NiFe-LDHs. A one-step hydrothermal method was employed to synthesize the bulk LDHs. In brief, for preparation of NiV-LDH, different mole ratios of $\mathrm{Ni} / \mathrm{V}$ solution $(1: 0,5: 1,3: 1,1: 1,1: 3$ and $0: 1$ for the synthesis of pure $\mathrm{Ni}(\mathrm{OH})_{2}, \mathrm{Ni}_{0.83} \mathrm{~V}_{0.17}-\mathrm{LDH}, \mathrm{Ni}_{0.75} \mathrm{~V}_{0.25}-\mathrm{LDH}, \mathrm{Ni}_{0.5} \mathrm{~V}_{0.5}-\mathrm{LDH}$, $\mathrm{Ni}_{0.25} \mathrm{~V}_{0.75}-\mathrm{LDH}$ and bare $\mathrm{V}$-based hydroxide, respectively) was obtained by mixing $\mathrm{NiCl}_{2}$ and $\mathrm{VCl}_{3}$ in $80 \mathrm{ml} \mathrm{H} \mathrm{O}$, while the total amount of metal ions $\left(\mathrm{Ni}^{2+}+\mathrm{V}^{3+}\right)$ was kept to $3.2 \mathrm{mmol}$. Afterwards, $0.3 \mathrm{~g}$ of urea was added, and the above mixture solution was transferred to a stainless-steel Teflon-lined autoclave, and heated in an oven at $120^{\circ} \mathrm{C}$ for $12 \mathrm{~h}$. After cooling the autoclave to room temperature, the resulting powder was washed by deionized water and ethanol three times, collected and then dried at $70^{\circ} \mathrm{C}$ overnight. As a reference, for preparation of $\mathrm{NiFe}-\mathrm{LDH}$, the same processes were followed except $\mathrm{FeCl}_{3}$ was used as iron source instead of $\mathrm{VCl}_{3}$, which was analogous to the literature ${ }^{25}$.}

Electrode preparation. A measure of $5 \mathrm{mg}$ of the obtained $\mathrm{LDH}$ powders were dispersed in the mixture solution of $1 \mathrm{ml} \mathrm{H}_{2} \mathrm{O}, 0.25 \mathrm{ml} \mathrm{2-propanol} \mathrm{and} 10 \mu \mathrm{l} 5 \%$ Nafion (ethanol solution) by sonication for $>1 \mathrm{~h}$. A measure of $2.5 \mu \mathrm{l}$ of the above suspension were drop-casted to a pre-polished GC electrode (diameter: $3 \mathrm{~mm}$ ), and dried at $50{ }^{\circ} \mathrm{C}$ for $15 \mathrm{~min}$ to evaporate the solvent.

Structure and surface characterization. X-ray diffraction measurements were carried out on Bruker X-ray diffraction diffractometer D5000 with $\mathrm{Cu} \mathrm{K \alpha}$ radiation. SEM images were taken on JEOL JSM-7000F instrument with energydispersive X-ray spectroscopy (EDS). TEM images were taken on JEOL JEM2100 TEM. Tapping mode AFM was performed to examine the surface morphology by a Dimension Icon AFM (Bruker, Santa Barbara, USA) on silicon wafer. Rectangular cantilevers with approximate dimensions of $125 \mu \mathrm{m}$ in length and $40 \mu \mathrm{m}$ in width (BudgetSensors Tap300Al-G) were used to perform the tapping mode experiments. The NanoScope Analysis software (version 1.50, Bruker) was used to analyse the recorded AFM data. A first-order polynomial-flattening algorithm was employed to remove surface tilt from height images. XPS measurements were conducted with an in-house spectrometer (PHI 5500) using monochromatized Al K $\alpha$ radiation
$(1,486.6 \mathrm{eV})$. The pressure in the analysis chamber was $\sim 5 \times 10^{-9}$ mbar during the measurement. Core peaks were analysed using a nonlinear Shirley-type background. The peak positions and areas were optimized by a weighted least-squares fitting method using 70\% Gaussian/30\% Lorentzian lineshapes. The powder was grinded and deposited on a conductive FTO glass. An electron flood gun was used to compensate the charging effects. The XPS spectra were energy calibrated by setting the adventitious carbon peak to $285 \mathrm{eV}$.

Electrochemical measurements. Electrolysis experiments were carried out in a polytetrafluoroethylene cell with an Autolab potentiostat with GPES electrochemical interface (Eco Chemie) in a standard three-electrode configuration, which was composed of working electrode (LDHs deposited on GC electrodes), counter electrode $(\mathrm{Pt}$ net) and reference electrode $(\mathrm{Ag} / \mathrm{AgCl})$. The electrolyte was $1 \mathrm{M} \mathrm{KOH}$, and the applied potentials were converted with respect to reversible hydrogen electrode (RHE), $E_{\mathrm{RHE}}=E_{\mathrm{Ag} / \mathrm{AgCl}}+0.059 \mathrm{pH}+0.197 \mathrm{~V}$, and overpotential $\eta=E_{\mathrm{RHE}}-1.23 \mathrm{~V}$.

First, before all the electrochemical measurements, a galvanostatic measurement at a fixed current density of $5 \mathrm{~mA} \mathrm{~cm}^{-2}$ was performed until a stable potential was obtained. Then LSV were measured from 0.2 to $0.7 \mathrm{~V}$ versus $\mathrm{Ag} / \mathrm{AgCl}$ with a slow scan rate of $2 \mathrm{mV} \mathrm{s}^{-1}$. By plotting overpotential $\eta$ against $\log (J)$ from LSV curves, Tafel slopes can be obtained. To test the stability of LDHs, a galvanostatic measurement at a fixed current density $(J)$ of $10 \mathrm{~mA} \mathrm{~cm}^{-2}$ was performed. ECSA were measured by $\mathrm{CV}$ at the potential window $0.2-0.3 \mathrm{~V}$ versus $\mathrm{Ag} / \mathrm{AgCl}$, with different scan rates of $20,40,60,80,100$ and $120 \mathrm{mV} \mathrm{s}^{-1}$. By plotting the $\Delta J=\left(J_{\mathrm{a}}-J_{\mathrm{c}}\right)$ at $0.25 \mathrm{~V}$ versus $\mathrm{Ag} / \mathrm{AgCl}$ against the scan rate, the linear slope that is twice of the double layer capacitance $\left(C_{\mathrm{dl}}\right)$ is used to represent ECSA. All the above measurements were carried out without ohmic-drop correction unless noted otherwise.

Turnover frequency. The TOF of LDH catalysts were calculated according to the following equation $(2)^{9}$,

$$
T O F=\frac{J A}{4 F m}
$$

where $J$ is the current density at a given overpotential, for example, in our cases $\eta=350 \mathrm{mV}, A$ is the surface area of the electrode $\left(0.07 \mathrm{~cm}^{2}\right), F$ is Faraday constant $\left(96,485 \mathrm{~s} \mathrm{~A} \mathrm{~mol}^{-1}\right)$ and $m$ is the number of moles of the metal on the electrodes. In our cases, we assumed all the metal sites were actively involved in the electrochemical reaction.

To compare the conductivities of LDHs, EISs were carried out in $1 \mathrm{M} \mathrm{KOH}$ with a three-electrode configuration, the frequency ranged from 0.1 to $10^{5} \mathrm{~Hz}$, with an a.c. amplitude of $10 \mathrm{mV}$ and overpotential bias of $350 \mathrm{mV}$.

The measurements of $\mathrm{O}_{2}$ were performed in an air-tight $\mathrm{H}$ shape cell, which was divided by a glass frit to two chambers. The working electrode, the $\mathrm{Ag} / \mathrm{AgCl}$ reference electrode and a magnetic stirring bar were inserted in one chamber of the cell, the Pt counter electrode was inserted in the other chamber. The cell was filled with $1 \mathrm{M} \mathrm{KOH}$ and degassed with helium for $>1 \mathrm{~h}$. The headspace of the compartment containing the working electrode was $23.6 \mathrm{ml}$. The electrolysis was carried out with a constant oxidation current of $1 \mathrm{~mA}$ for $60 \mathrm{~min}$. A measure of $500 \mu \mathrm{l}$ of the gas sample in the compartment containing the working electrode was transferred by a specific syringe to the gas chromatography, (Shimadzu) where the amount of $\mathrm{O}_{2}$ evolution was determined. The Faradaic efficiency was determined from the total amount of charge $Q(C)$ passed through the cell and the total amount of the produced $\mathrm{O}_{2} n_{\mathrm{O} 2}(\mathrm{~mol})$ : Faradaic efficiency $=4 F \times n_{\mathrm{O} 2} / Q$, where $F$ is the Faraday constant, assuming the four electrons are needed to produce one oxygen molecule.

DFT calculation. Calculations were carried out with DFT implanted in the Vienna $\mathrm{Ab}$ initio Simulation Package (VASP) ${ }^{39-42}$ to give a better understanding for the superior activity of $\mathrm{Ni}_{0.75} \mathrm{~V}_{0.25}$-LDH. Perdew-Burke-Ernzerhof $(\mathrm{PBE})^{43}$ exchangecorrelation functional and projector augmented-wave (PAW) ${ }^{44}$ pseudo-potential were adopted. An energy cutoff of $400 \mathrm{eV}$ was applied for the plane-wave basis set. A $2 \times 2$ supercell was used with one of the $\mathrm{Ni}$ atom substituted by $\mathrm{Fe}$ or V. A $7 \times 7$ Monkhorst-Pack K-point grid was applied for the sampling of Brillouin zone. To describe the transition metal elements, DFT $+\mathrm{U}^{45}$ method have been used with the $\mathrm{U}$ values from ref. $35, \mathrm{U}-\mathrm{J}=3.8 \mathrm{eV}$ for $\mathrm{Ni}^{2+}$ and $\mathrm{U}-\mathrm{J}=4.3 \mathrm{eV}$ for $\mathrm{Fe}^{3+}$ and $\mathrm{U}-\mathrm{J}=3.4 \mathrm{eV}$ for $\mathrm{V}^{3+}$ species. One proton of the material is removed to create the metal ion at $3+$ oxidation state. The structures were optimized until the maxima force on the atoms was smaller than $0.02 \mathrm{eV} / \AA$.

Data availability. The data that support the findings of this study are available from the corresponding author upon request.

\section{References}

1. McCrory, C. C. L., Jung, S., Peters, J. C. \& Jaramillo, T. F. Benchmarking heterogeneous electrocatalysts for the oxygen evolution reaction. J. Am. Chem. Soc. 135, 16977-16987 (2013). 
2. Galán-Mascarós, J. R. Water oxidation at electrodes modified with earth-abundant transition-metal catalysts. ChemElectroChem. 2, 37-50 (2015).

3. Chen, G. et al. Interfacial effects in iron-nickel hydroxide-platinum nanoparticles enhance catalytic oxidation. Science 344, 495-499 (2014).

4. Lu, Z. et al. Three-dimensional NiFe layered double hydroxide film for high-efficiency oxygen evolution reaction. Chem. Commun. 50, 6479-6482 (2014)

5. Trotochaud, L., Young, S. L., Ranney, J. K. \& Boettcher, S. W. Nickel-iron oxyhydroxide oxygen-evolution electrocatalysts: the role of intentional and incidental iron incorporation. J. Am. Chem. Soc. 136, 6744-6753 (2014).

6. Friebel, D. et al. Identification of highly active Fe sites in $(\mathrm{Ni}, \mathrm{Fe}) \mathrm{OOH}$ for electrocatalytic water splitting. J. Am. Chem. Soc. 137, 1305-1313 (2015).

7. Gong, M. \& Dai, H. A mini review of NiFe-based materials as highly active oxygen evolution reaction electrocatalysts. Nano Res. 8, 23-39 (2015).

8. Gong, M. et al. An advanced Ni-Fe layered double hydroxide electrocatalyst for water oxidation. J. Am. Chem. Soc. 135, 8452-8455 (2013).

9. Song, F. \& Hu, X. Exfoliation of layered double hydroxides for enhanced oxygen evolution catalysis. Nat. Commun. 5, 4477 (2014).

10. Long, X. et al. A strongly coupled graphene and FeNi double hydroxide hybrid as an excellent electrocatalyst for the oxygen evolution reaction. Angew. Chem. Int. Ed. 53, 7584-7588 (2014).

11. Ma, W. et al. A superlattice of alternately stacked $\mathrm{Ni}-\mathrm{Fe}$ hydroxide nanosheets and graphene for efficient splitting of water. ACS Nano 9, 1977-1984 (2015).

12. Louie, M. W. \& Bell, A. T. An investigation of thin-film Ni-Fe oxide catalysts for the electrochemical evolution of oxygen. J. Am. Chem. Soc. 135, 1232912337 (2013).

13. Valdez, R., Grotjahn, D. B., Smith, D. K., Quintana, J. M. \& Olivas, A. Nanosheets of $\mathrm{Co}-(\mathrm{Ni}$ and $\mathrm{Fe})$ layered double hydroxides for electrocatalytic water oxidation reaction. Int. J. Electrochem. Sci. 10, 909-918 (2015).

14. Liang, H. et al. Hydrothermal continuous flow synthesis and exfoliation of NiCo layered double hydroxide nanosheets for enhanced oxygen evolution catalysis. Nano Lett. 15, 1421-1427 (2015).

15. Burke, M. S., Kast, M. G., Trotochaud, L., Smith, A. M. \& Boettcher, S. W Cobalt-iron (oxy)hydroxide oxygen evolution electrocatalysts: the role of structure and composition on activity, stability, and mechanism. J. Am. Chem. Soc. 137, 3638-3648 (2015)

16. Liang, J. et al. Topochemical synthesis, anion exchange, and exfoliation of $\mathrm{Co}-\mathrm{Ni}$ layered double hydroxides: a route to positively charged $\mathrm{Co}-\mathrm{Ni}$ hydroxide nanosheets with tunable composition. Chem. Mater. 22, 371-378 (2010).

17. Diaz-Morales, O., Ledezma-Yanez, I., Koper, M. T. M. \& Calle-Vallejo, F. Guidelines for the rational design of Ni-based double hydroxide electrocatalysts for the oxygen evolution reaction. ACS Catal. 5, 5380-5387 (2015).

18. Tan, Z. A. et al. Solution-processed nickel acetate as hole collection layer for polymer solar cells. Phys. Chem. Chem. Phys. 14, 14217-14223 (2012).

19. De Jesus, J. C., González, I., Quevedo, A. \& Puerta, T. Thermal decomposition of nickel acetate tetrahydrate: an integrated study by TGA, QMS and XPS techniques. J. Mol. Catal. A: Chem. 228, 283-291 (2005).

20. Mansour, A. N. Characterization of $\mathrm{NiO}$ by XPS. Surf. Sci. Spectra 3, 231-238 (1994).

21. Biesinger, M. C. et al. Resolving surface chemical states in XPS analysis of first row transition metals, oxides and hydroxides: $\mathrm{Cr}, \mathrm{Mn}, \mathrm{Fe}, \mathrm{Co}$ and Ni. Appl. Surf. Sci. 257, 2717-2730 (2011)

22. Chen, H. et al. 3D open-framework vanadoborate as a highly effective heterogeneous pre-catalyst for the oxidation of alkylbenzenes. Chem. Mater. 25, 5031-5036 (2013)

23. Biesinger, M. C., Lau, L. W. M., Gerson, A. R. \& Smart, R. S. C. Resolving surface chemical states in XPS analysis of first row transition metals, oxides and hydroxides: Sc, Ti, V, Cu and Zn. Appl. Surf. Sci. 257, 887-898 (2010).

24. Silversmit, G., Depla, D., Poelman, H., Marin, G. B. \& De Gryse, R. Determination of the V2p XPS binding energies for different vanadium oxidation states $\left(\mathrm{V}^{5+}\right.$ to $\left.\mathrm{V}^{0+}\right)$. J. Electron Spectrosc. 135, 167-175 (2004).

25. Luo, J. et al. Water photolysis at $12.3 \%$ efficiency via perovskite photovoltaics and Earth-abundant catalysts. Science 345, 1593-1596 (2014).

26. Song, F. \& Hu, X. Ultrathin cobalt-manganese layered double hydroxide is an efficient oxygen evolution catalyst. J. Am. Chem. Soc. 136, 16481-16484 (2014).

27. Ma, T. Y., Dai, S., Jaroniec, M. \& Qiao, S. Z. Graphitic carbon nitride nanosheet-carbon nanotube three-dimensional porous composites as highperformance oxygen evolution electrocatalysts. Angew. Chem. Int. Ed. 53, 7281-7285 (2014).

28. Walter, M. G. et al. Solar water splitting cells. Chem. Rev. 110, 6446-6473 (2010).

29. Nai, J. et al. Efficient electrocatalytic water oxidation by using amorphous Ni-Co double hydroxides nanocages. Adv. Energy. Mater. 5, 1401880 (2015)

30. Huynh, M., Shi, C., Billinge, S. J. L. \& Nocera, D. G. Nature of activated manganese oxide for oxygen evolution. J. Am. Chem. Soc. 137, 14887-14904 (2015).
31. Smith, R. D. L., Prévot, M. S., Fagan, R. D., Trudel, S. \& Berlinguette, C. P. Water oxidation catalysis: electrocatalytic response to metal stoichiometry in amorphous metal oxide films containing iron, cobalt, and nickel. J. Am. Chem Soc. 135, 11580-11586 (2013).

32. Lopes, T., Andrade, L., Ribeiro, H. A. \& Mendes, A. Characterization of photoelectrochemical cells for water splitting by electrochemical impedance spectroscopy. Int. J. Hydrogen Energ. 35, 11601-11608 (2010).

33. Long, X., Xiao, S., Wang, Z., Zheng, X. \& Yang, S. Co intake mediated formation of ultrathin nanosheets of transition metal LDH-an advanced electrocatalyst for oxygen evolution reaction. Chem. Commun. 51, 1120-1123 (2015).

34. Jaramillo, T. F. et al. Identification of active edge sites for electrochemical H2 evolution from $\mathrm{MoS}_{2}$ nanocatalysts. Science 317, 100-102 (2007).

35. Liao, P., Keith, J. A. \& Carter, E. A. Water oxidation on pure and doped hematite (0001) surfaces: prediction of $\mathrm{Co}$ and $\mathrm{Ni}$ as effective dopants for electrocatalysis. J. Am. Chem. Soc. 134, 13296-13309 (2012).

36. Man, I. C. et al. Universality in oxygen evolution electrocatalysis on oxide surfaces. ChemCatChem. 3, 1159-1165 (2011).

37. Calle-Vallejo, F. \& Koper, M. T. M. First-principles computational electrochemistry: achievements and challenges. Electrochim. Acta 84, 3-11 (2012).

38. Li, Y., Zhang, L., Xiang, X., Yan, D. \& Li, F. Engineering of ZnCo-layered double hydroxide nanowalls toward high-efficiency electrochemical water oxidation. J. Mater. Chem. A 2, 13250-13258 (2014).

39. Kresse, G. \& Hafner, J. Abinitio molecular-dynamics for liquid-metals. Phys. Rev. B 47, 558-561 (1993).

40. Kresse, G. \& Hafner, J. Ab-initio molecular-dynamics simulation of the liquid-metal amorphous-semiconductor transition in germanium. Phys. Rev. B 49, 14251-14269 (1994).

41. Kresse, G. \& Furthmuller, J. Efficient iterative schemes for ab initio total-energy calculations using a plane-wave basis set. Phys. Rev. B 54, 11169-11186 (1996).

42. Kresse, G. \& Furthmuller, J. Efficiency of ab-initio total energy calculations for metals and semiconductors using a plane-wave basis set. Comp. Mat. Sci. 6, 15-50 (1996)

43. Perdew, J. P., Burke, K. \& Ernzerhof, M. Generalized Gradient Approximation Made Simple. Phys. Rev. Lett. 77, 3865-3868 (1996).

44. Blöchl, P. E. Projector augmented-wave method. Phys. Rev. B 50, 17953-17979 (1994).

45. Dudarev, S. L., Botton, G. A., Savrasov, S. Y., Humphreys, C. J. \& Sutton, A. P Electron-energy-loss spectra and the structural stability of nickel oxide: an LSDA + U study. Phys. Rev. B 57, 1505-1509 (1998).

\section{Acknowledgements}

We thank Beatrice Johansson from KTH, Dr Valentina Leandri, Chao Xu and Sareh Ahmed from Uppsala University for their help in characterizations of materials. We acknowledge the financial support of this work by Swedish Energy Agency, the Knut and Alice Wallenberg Foundation, the Swedish Research Council, the National Natural Science Foundation of China $(21120102036,91233201)$ and the National Basic Research Program of China (973 program, 2014CB239402).

\section{Author contributions}

K.F. and H.C. contributed equally to this paper. K.F. designed the experiments, fabricated and measured the devices, and wrote the paper. H.C. carried out the X-ray diffraction, SEM and TEM characterization, analysed the data and helped to revise the paper. Y.J. and Y.L. did the DFT calculation; H.H. and P.C. carried out the AFM measurement; and B.P. and H.R. carried out and analysed the XPS measurements. Q.D. and F.L. contributed to the discussion of the paper. L.S. supervised the project and wrote the paper.

\section{Additional information}

Supplementary Information accompanies this paper at http://www.nature.com/ naturecommunication

Competing financial interests: The authors declare no competing financial interests

Reprints and permission information is available online at http://npg.nature.com/ reprintsandpermissions/

How to cite this article: Fan, K. et al. Nickel-vanadium monolayer double hydroxide for efficient electrochemical water oxidation. Nat. Commun. 7:11981 doi: 10.1038/ncomms11981 (2016)

This work is licensed under a Creative Commons Attribution 4.0 International License. The images or other third party material in this article are included in the article's Creative Commons license, unless indicated otherwise in the credit line; if the material is not included under the Creative Commons license, users will need to obtain permission from the license holder to reproduce the material To view a copy of this license, visit http://creativecommons.org/licenses/by/4.0/ 